\title{
DIASPORA HAITIANA: PRIMEIROS ESTUDOS SOBRE IMPACTOS PARA O DESENVOLVIMENTO URBANO E REGIONAL NAS REGIÕES SUL E NORTE DO BRASIL
}

\author{
Maria de Lourdes Bernartt ${ }^{l}$ \\ Giovanna Pezarico ${ }^{2}$ \\ Leonel Piovezana ${ }^{3}$ \\ Sandra de Ávila Farias Bordignon ${ }^{4}$ \\ Taize Giacomini
}

\begin{abstract}
Resumo: É sabido que o desenvolvimento brasileiro contou, em grande medida, com a participação direta de migrantes transnacionais que desde muito cedo chegaram ao Brasil (1530) em busca de melhores condições de vida. É sabido ainda que, pelas condições subhumanas e degradantes a que a maioria esteve e/ou está exposta, e pela significativa contribuição no crescimento econômico, social e cultural do Brasil, sentimo-nos em dívida histórica em relação a eles(as). Em períodos mais recentes, registra-se um fluxo contínuo de entrada de migrantes e refugiados no país com os mesmos objetivos, e, basicamente, sob as mesmas condições. A partir de 2010, presencia-se um novo fenômeno- caracterizado pela diáspora haitiana, especialmente pela mobilidade espacial de trabalhadores, já considerada uma das maiores, nos últimos 100 anos. Visando contribuir para a questão, o texto tem o propósito de socializar primeiros dados e resultados de estudos realizados a partir de 2013, por pesquisadores de universidades das regiões Sul e Norte do Brasil.
\end{abstract}

Palavras-chave: Migração. Diáspora haitiana. Desenvolvimento urbano e regional. Sul e Norte.

\footnotetext{
Docente do Programa de Pós-Graduação em Desenvolvimento Regional (PPGDR) e do Programa de PósGraduação em Letras, da UTFPR Câmpus Pato Branco. Graduação em Letras. Mestrado e Doutorado em Educação (UNICAMP). Vice-Líder do Centro de Pesquisa e Apoio ao Desenvolvimento Regional (CEPAD). Líder do Grupo de Estudos e Pesquisa sobre a Linguagem (GEPEL). Membro do Grupo de Estudos sobre Imigracõos para o Oeste de Santa Catarina (GEIROSC). Editora Associada da Revista Pedagógica da Unochapecó.

2 Docente do Programa de Pós-Graduação em Desenvolvimento Regional (PPGR) da UTFPR Câmpus Pato Branco. Graduação em Administração. Mestrado e Doutorado em Tecnologia (PPGTE).

3 Docente do Programa de Pós-Graduação em Educação (PPGE), e do Programa de Pós-Graduação em Políticas Sociais e Dinâmicas Regionais, da UNOCHAPECÓ. Graduação em História e Estudos Sociais. Mestrado e Doutorado em Desenvolvimento Regional.

4 Mestranda do Programa de Pós-Graduação em Educação (PPGE), da UNOCHAPECÓ. Graduada em Pedagogia. Pedagoga da UFFS. Líder do Grupo de Estudos sobre Imigrações para o Oeste de Santa Catarina (GEIROSC).

5 Mestranda do Programa de Pós-Graduação em Desenvolvimento Regional, da UTFPR Câmpus Pato Branco.
} 


\begin{abstract}
It is known that the Brazilian development included, to a large extent, the direct participation of transnational migrants who arrived in Brazil early (1530), in search of better living conditions. It is still known that, for the subhuman degrading conditions the majority was and / or is exposed, and for the significant contribution in the economical, social and cultural growth of Brazil, we feel in historical debt regarding them. In more recent periods, a continuous flow of entry of migrant and refugees is registered in the country with the same objectives, and, basically, under the same conditions. From 2010, it is witnessed a new phenomenon - characterized by the Haitian diaspora, especially the spatial mobility of workers, already considered one of the largest in the 1 ast 100 years. To contribute to the issue, the text has the purpose of socializing first data and results of studies conducted from 2013, by researchers from universities of South and North regions of Brazil.
\end{abstract}

Keywords: Migration. Haitian diaspora. Urban and regional development. South and North.

\title{
INTRODUÇÃO
}

As migrações transnacionais que marcam o século XXI assumem, cada vez mais, aspectos relevantes nas sociedades locais, e essa mobilidade de força de trabalho (SASSEN, 1998) tem se tornado expressão social dos processos recentes da divisão internacional do trabalho e de seus impactos territoriais.

Diante disso, pensa-se que, para entender e compreender melhor um fenômeno do real, uma das estratégias é localizá-lo no movimento da materialidade do cotidiano dos homens e mulheres, em seu tempo histórico e em seus espaços territoriais. Assim, falar em diáspora/migração/imigração/ é falar da própria história da humanidade e de cada homem em si, pois, em dado momento de sua trajetória humana, o homem migra, imigra, e/ou emigra, porque consiste em seu modus operandi por melhores condições de sobrevivência. Pode-se dizer, então, que todos somos, em alguma medida, migrantes.

É fato que, na circunferência de nosso quintal, nós, brasileiros, somos descendentes de migrantes e nos vimos nascer e crescer em um país de migrantes. É fato que o Brasil, desde os seus mais remotos rincões, protagonizou cenas de migrações históricas, desde que aqui aportaram os portugueses no contexto da colonização, seguidas pelo tráfego de africanos, tornados escravos. Registros desse período (até 1850) mencionam a entrada de 4 milhões de cativos na colônia (CHIARELLO, 2011). Um outro cenário foi potencial para a entrada de uma grande leva de imigrantes ao país - a extinção da escravatura e com isso a necessidade de trabalhadores no território brasileiro e a não absorção de trabalhadores europeus no processo nascente de industrialização. A conjugação de tais elementos propi- 
ciou a entrada de grande número de imigrantes europeus no Brasil, a partir da década de 1870 (BRITO, 2004). Desse período a 1930 registra-se a vinda significativa de imigrantes europeus para a América, cujas estimativas apontam cerca de 40 milhões (OLIVEIRA, 2002). Desse modo, marca-se aí o início da politica migratória brasileira.

A mobilidade espacial da força de trabalho para o Brasil não é inédita. Ela surge com a libertação dos escravos (1888), quando vieram para o país levas de italianos, portugueses, espanhóis, alemães, poloneses, dentre outras nacionalidades, principalmente para as grandes fazendas de café no Estado de São Paulo, bem como para os três estados da região sul do Brasil. Em relação às regiões sudoeste do Paraná e oeste de Santa Catarina, locus desta pesquisa, ocorreu significativa mobilidade espacial de força de trabalho nas décadas de 1950 e 1960 vinda do Noroeste do Rio Grande do Sul, formada por agricultores, descendentes de italianos e alemães, em sua grande maioria. Neste início de século XXI, a região sul do Brasil tem se tornado palco de uma nova mobilidade espacial da força de trabalho oriunda da América Central - Haiti, especialmente para as cidades de Chapecó-SC e Pato Branco-PR. Não é mais possível ignorar essa parcela populacional, visto que essas pessoas estão presentes em grandes empresas e constituem um contingente significativo que passa a influenciar no desenvolvimento local e regional. Tal situação, nessas regiões, ainda é parcamente estudada pela academia, e é de se prever que existem impactos para esses trabalhadores, bem como para a sociedade pato-branquense e chapecoense, em geral. Em razão de se observar a vinda de um grande número de trabalhadores estrangeiros, a partir de 2010, a temática em questão tem despertado no sul do Brasil o interesse de pesquisadores, dentre eles, os do Programa de Pós-Graduação em Desenvolvimento Regional - PPGDR, da Universidade Tecnológica Federal do Paraná - UTFPR, Câmpus Pato Branco e do Programa de Pós-Graduação em Educação, da Universidade Comunitária Regional de Chapecó - Unochapecó, dentre outros. Diante desse quadro, o interesse está em investigar o modo como ocorre a mobilidade espacial da força de trabalho haitiana para ambas as regiões, neste início do século XXI e, principalmente como ocorre o processo de inserção escolar e não escolar, e linguística de tais trabalhadores nesses contextos e, com isso, qual a contribuição destes para o desenvolvimento local.

Neste texto apresentam-se alguns resultados de estudos realizados em programas de pós-graduação de universidades dos Estados do Paraná, Santa Catarina e Rondônia. 


\section{ESCLARECENDO CONCEITOS: MIGRAR, EMIGRAR, IMIGRAR COMO DIREITO HUMANO}

Segundo o Alto Comissariado das Nações Unidas para os Refugiados (ACNUR, 2014), aproximadamente 60 milhões de pessoas têm sido forçadas a se deslocar no mundo e fazer as travessias em embarcações precárias pelo Mediterrâneo, tornando-se manchetes de jornais, está cada vez mais comum ver os termos 'refugiado' e 'migrante' confundidos, tanto nos discursos da mídia, quanto do público em geral.

Estes estão inclusos nos 41,4\% que estão em mobilidade das 7,8 bilhões de pessoas no mundo (ONU, 2013, apud IMDH, 2015). Entre estes se encontram as várias pessoas que estão em mobilidade no mundo:

Tabela 1: Número de pessoas em mobilidade no mundo

\begin{tabular}{|c|c|}
\hline Migrantes internacionais legais: & 252 milhões \\
\hline Migrantes internacionais irregulares: & 42 milhões \\
\hline Refugiados: & 51,2 milhões \\
\hline Apátridas: & 12 milhões \\
\hline Marítimos: & 1,5 milhão \\
\hline Pescadores embarcados: & 15 milhões \\
\hline Nômades - ciganos sem país: & 12 milhões \\
\hline Nômades de gado no oriente: & 40 milhões \\
\hline Estudantes internacionais: & 7 milhões \\
\hline Migrantes internos: & 800 milhões \\
\hline Trabalhadores que saem do seu município: & 1 bilhão \\
\hline Turistas anuais: & 1,5 bilhão \\
\hline
\end{tabular}

Fonte: IMDH,2015.

A mobilidade humana observada no Brasil insere-se nesse contexto, uma vez que que a formação do povo brasileiro se dá também com base nesses movimentos.

Migrar é um direito humano e como tal se caracteriza como fenômeno mundial. Entende-se por migrante aquele que se desloca, imigrante aquele que chega e emigrante aquele que sai (ZAMBERLAN et al, 2014).

Sayad (1998) entende que "um imigrante é essencialmente uma força de trabalho, e uma força de trabalho provisória, temporária, em trânsito (p.54)". O autor dá ao termo a sua condição de busca pelo trabalho que mantem o movimento, sendo assim, fator essencial ao se fazer imigrante.

A compreensão que contemplam o entendimento dos processos sociais relacionados aos fluxos de pessoas entre países, regiões e continentes passa pela identificação de que sob o tema da migração inter- 
nacional estão incluídos fenômenos distintos, com grupos sociais e implicações que se apresentam sob as mais diversas formas. Se, de um lado, nos interessa entender esse termo como forma de legitimar e garantir a visibilidade do que estamos mencionando, nos fóruns internacionais e nacionais, de outro, carregamos o desafio de concretizar, em dimensões teórico-conceituais, as amplas e complexas interligações de instâncias sociais, econômicas, culturais, jurídicas e institucionais, entre outras, que abrangem os movimentos de pessoas que cruzam fronteiras de Estados-nação.

\footnotetext{
Quando o tema é migração, assuntos relacionados aos direitos sociais dos imigrantes estão sempre presentes. Respeito, dignidade, reconhecimento e melhorias de vida são os assuntos que norteiam este debate. No entanto, tratar de questões relacionadas aos direitos políticos também é de suma importância, já que direitos sociais, políticos e civis são os três pilares do conceito de cidadania. (BARATA, 2012). ${ }^{6}$
}

As teorias da migração internacional podem ser classificadas em dois grupos; no primeiro entram os modelos que determinam o surgimento do movimento internacional contemporâneo; no segundo estão as teorias que explicam a perseverança dos fluxos migratórios e a sua continuidade no tempo, de acordo com Patarra (2006).

Para melhor entendimento, salienta-se que o documento mais importante, no que se refere aos direitos humanos, é a "Declaração Universal dos Direitos Humanos", promulgada pela Assembleia Geral das Nações Unidas (1948), "como ideal comum a ser atingido por todos os povos e todas as nações". Nesse documento, o direito de ir e vir aparece assegurado pelo art. 13, que dispõe: "I) - Todo homem tem direito à liberdade de locomoção e residência dentro das fronteiras de cada Estado. II) - Todo o homem tem direito de deixar qualquer país, inclusive o próprio, e a este regressar." Nele estão incluídas as aspirações humanas manifestadas em tantas lutas e movimentos libertários que se desenvolveram, com maior ou menor êxito, durante o longo período que percorreram mais de dois milênios.

O movimento de ir e vir, próprio do ser humano, materializa-se nos fluxos migratórios caracterizados por sujeitos ${ }^{7}$, assim definidos:

a) Migrante - é toda pessoa em movimento com a intenção ou não de residir em outro local. Quando parte é EMIGRANTE, quando chega ao país de destino denomina-se IMIGRANTE. O imigrante pode apresentar-se documentado; pode ficar indocumentado (entra com a documentação em dia, mas deixa vencer o prazo sem renovação, ficando em situação

\footnotetext{
Disponível em: http://oestrangeiro.org/2012/06/17/migrar-e-um-direito-humano/

Documento do "Fórum Permanente da Mobilidade Humana do RS" (2013).
} 
irregular) e pode ser clandestino (ou seja entra sem a documentação exigida pelo país que o acolhe e aí permanece sem regularizar os documentos. A mídia e muitos governos o tipificam pejorativamente (criminaliza - como imigrante ilegal, que não merece direito à cidadania).

b) Refugiado - pessoa que por via de fato ou temor de perseguição (raça, religião, política...) ou devido à grave e generalizada violação de direitos humanos é obrigada a deixar o seu país de nacionalidade para buscar refúgio em outro país.

c) Apátrida - pessoa que não é considerado como um nacional por nenhum Estado.

d) Vítima de tráfico de pessoas (tráfico humano). Pessoa (brasileira ou estrangeira) submetida à ação criminosa: recrutada, transferida, por fraude, engano, força, rapto, abuso de autoridade com a finalidade de exploração sexual, trabalho escravo ou serviços forçados, remoção de órgãos, adoção ilegal.

e) Estudante internacional: pessoa que realiza seu curso superior ou pós em outro país na busca de aprimoramento pessoal e profissional, seja de forma independente, por meio de acordos, convênios de programas governamentais ou interinstitucionais.

f) Marítimo - pessoa que trabalha no porto, nos navios comerciais, de turismo ou em atividades pesqueiras.

O Instituto Migrações e Direitos Humanos (IMDH, 2015) contribui para os estudos destacando a diferença entre migração e refúgio. Migração é concebida como movimento "voluntário", podendo ser regular ou não, geralmente motivada por questões econômicas, culturais, não havendo fundado temor de perseguição no país de origem. Inclui-se aqui também a migração por razões ambientais (não há, na legislação, o refugiado ambiental). Refúgio, por sua vez, consiste em deslocamento forçado de seu país de origem devido à perseguição ou fundado temor de perseguição ou ainda devido à grave e generalizada violação de direitos humanos. Ao contrário do migrante, o refugiado não pode retornar ao seu país de origem.

Conforme o IMDH (2015) ressalta que, no mundo são 59,5 milhões de pessoas forçadas a deixar sua casa. Destes, existem 19,5 milhões de refugiados. Muitos países do mundo têm uma presença superior a $10 \%$ da população. Já no Brasil os migrantes internacionais não passam de $1 \%$ da população. Para ilustrar esse cenário, apresentamos o número de solicitantes de Refúgio, nos últimos dez anos, segundo registros obtidos na Polícia Federal pelo IMDH (2015). 
Tabela 2: Solicitantes de Refúgio, nos últimos 10 anos, segundo registros da Polícia Federal

\begin{tabular}{|l|l|l|}
\hline Ano & $\begin{array}{l}\text { Número total de } \\
\text { solicitantes de refúgio }\end{array}$ & Solicitantes de refúgio Haitianos \\
\hline 2004 & 65 & - \\
\hline 2005 & 20 & - \\
\hline 2006 & 709 & - \\
\hline 2007 & 322 & - \\
\hline 2008 & 494 & - \\
\hline 2009 & 522 & - \\
\hline 2010 & 538 & 454 \\
\hline 2011 & 1.070 & 2.566 \\
\hline 2012 & 961 & 3.274 \\
\hline 2013 & 6.109 & 11.755 \\
\hline 2014 & 12.049 & 16.982 \\
\hline
\end{tabular}

Fonte: IMDH, 2015.

\section{PARA ENTENDER A DIÁSPORA HAITIANA}

De acordo com estudiosos, dentre eles, Handerson (2015), desde 1990 a diaspora haitiana tem estado na pauta de diversos estudos, tanto (trans)nacionais, quanto no discurso político. A literatura menciona esse movimento acentuadamente para os Estados Unidos, França, Canadá e Caribe. Sobre isso, o Ministério dos Haitianos Residentes no Exterior estima que há cerca de 4 a 5 milhões de haitianos em mobilidade, em termos globais, o que representa a metade da população haitiana, estimada em 10.413.211, em 2013, de acordo com dados do Institut Haitien Statistique et d'Informatique (HANDERSON, 2015).

Destes, destaca o autor, cerca de 7 mil passaram pela Tríplice Fronteira Brasil, Colômbia e Peru, entre 2010 e 2013, estimando-se atualmente haver entre 35 a 40 mil no Brasil.

Para este estudioso, o termo diáspora merece novos estudos, em razão dos constantes fluxos de mobilidade da população haitiana em escala supranacional, tendo sido esse o foco de sua tese de doutorado ${ }^{8}$. Segundo o

Diaspora, as dinâmicas da mobilidade haitiana no Brasil, no Suriname e na Guiana Francesa, Tese defendida em 2015, na Universidade Federal do Rio de Janeiro, no Programa de Pós-Graduação em Antropologia Social (HANDERSON, 2015). 
autor, o sonho da maioria dos haitianos é "pati" (partir) ou vwayaje (viajar), tanto é assim que basicamente em toas as famílias há algum membro em peyi etranje (país estrangeiro). Tal fato origina-se ainda na fundação da colônia, pois a mobilidade já se fez presente na vinda de africanos escravizados, por meio do comércio transatlântico. Posteriormente, com a luta pela independência, entre 1793 e 1803 e com a libertação dos escravizados, constituiu-se um novo costume de marronage ${ }^{9}$, mobilidade e imigração.

Handerson (2015) destaca quatro grandes fluxos da mobilidade haitiana em diferentes períodos, os quais consideramos importante mencionar. O primeiro fluxo para o exterior ocorreu no período em que as forças armadas dos EUA ocuparam o Haiti (1915-1943) e República Dominicana, concomitantemente (1912-1924). De "30.000 a 40.000 haitianos, chamados braceros, migravam temporariamente todos os anos para Cuba, entre 1913 e 1931" (WOODING; MOSELEY-WILLIAMS, 2009, p. 36 apud HANDERSON, 2015, p. 69). Em 1944 estimava-se haver mais de 80.000 em plantações em Cuba, assevera o autor.

O segundo fluxo de migração, apontado pelo autor, ocorre quando os EUA se tornaram mais familiares no contexto haitiano, o que levou à obrigatoriedade da língua inglesa nas escolas, no governo de Elie Lescot (1941-1946), assim como aumentaram sobremaneira as igrejas protestantes e americanas.

E, eis que, na década de 1950, os filhos da elite haitiana estudavam nos Estados Unidos, vistos "como nova possibilidade para emigrar" (HANDERSON, 2015, p. 70), e com isso, já em 1940, os haitianos eram aproximadamente 5.000, particularmente em Nova York (ICART, 1987, p. 37, apud HANDERSON, 2015, p. 70). A partir de 1960, no período ditatorial de François Duvalier (1957-1971) amplia-se a emigração no país, para as diferentes classes, gerações e regiões, diz o autor, e os dados mostram que entre 1964 e 1971(ano da morte de Duvalier) nos Estados Unidos foram registradas as entradas de 40.100 imigrantes e 100.000 não-imigrantes oriundos do Haiti (AUDEBERT, 2012, p. 26-27, apud HANDERSON, 2015, p. 71).

Em meio à ditadura, menciona o autor, nas décadas de 1960 e 1970, grande leva de intelectuais e profissionais instalaram-se em Nova York, Boston, Chicago, Miami, Montreal, no Canadá, no Senegal, no Benin e no República do Congo. Nesse mesmo período, são estimados entre 40.000 e 70.000 haitianos nas Bahamas, contudo, a partir de 1963 este país iniciou a deportação de indocumentados, o que chegou nos últimos decênios a 6.000 anualmente. E do final de 1960, com 100 haitianos na França, e início de

Marronage origina-se da palavra cimarronada e relaciona-se com diaspora, com mobilidade de pessoa (HANDERSON, 2015). 
1970 com 400 (cerca de 70\% estudantes), e nas décadas de 1980 e 1990 este número aumentou significativamente na década seguinte, saltando para 20.000 (DELACHET-GUILLON, 1996, p. 66, apud HANDERSON, 2015, p. 72). Ainda a partir de 1963 os haitianos começaram a chegar na Guiana Francesa, para trabalhar nas plantações de bananas.

$\mathrm{O}$ autor destaca que esse segundo fluxo migratório chamou a atenção pelo fenômeno boat people $e^{10}$ e atingiu seu ápice nos anos de 1977 a 1981 quando cerca de 50.000 a 70.000 haitianos chegaram com vida às costas da Flórida, quando muitos morreram em alto mar. ${ }^{11}$

Foi nesse contexto que se iniciou a mobilização de diversas instituições religiosas, políticas, associativas, militantes na defesa dos direitos humanos dessas pessoas, tais como o National Council of Churches (organização religiosa norte americana), o Black Caucaus (organização representante dos negros no Congresso norte americano), e o Haitian Refugee Center (Centro de Refugiados Haitianos) (HANDERSON, 2015, p. 72).

O terceiro fluxo imigratório ocorreu na metade de 1990, com o golpe de Estado e deportação do ex-presidente Jean-Bertrand Aristide, quando cerca de 46.000 boat people foram apanhados em alto mar e transportados aos campos de detenção de Guantânamo Bay, em Cuba, onde alguns ficaram presos por mais de um ano. E, neste local, dos $72 \%$ dos 36.596 interrogados pelos Serviços de Imigração, foram reconduzidos ao país de origem, tendo seu pedido de refúgio negado (LITLE, 1997, p. 3, apud HANDERSON , 2015, p. 73).

Em 1991, diz-nos o autor, com base em seus estudos, mais de 100.000 haitianos saíram do país e dos países onde solicitaram refúgio Estados Unidos, República Domincana, Guadalupe, Guiana Francesa e Bahamas, alguns negaram o estatuto de refugiados. Foram considerados imigrantes econômicos, salvo os que conseguiram comprovar perseguição política, religiosa ou étnica, de acordo com o prescrito pela Convenção de Genebra.

O quarto fluxo de imigração haitiana iniciou-se a partir de 2010, pelo cenário empobrecido do Haiti, o que causa insegurança: política, socioeconômica, alimentícia, educacional, saúde, de saneamento básico, acentuada ainda mais pela ocorrência do terremoto de janeiro deste mesmo ano. Esse conjunto de fatores potencializou a mobilidade dos haitianos em volume e ampliou os espaços internacionais de procura (HANDERSON, 2015).

10 O termo "Boat people" refere-se aos imigrantes haitianos embarcados em direção a Miami ou às ilhas caribenhas, como Bahamas, Grand Turk, Cuba, dentre outras, para chegar a Miami (HANDERSON, 2015, p. 72).

11 Vários problemas causaram o naufrágio das embarcações, dentre eles: problemas técnicos ou naufrágio provocado por agentes norte-americanos, que afundavam as embarcações. (HANDERSON, 2015). 
Com efeito, a tragédia do terremoto provocou um duplo movimento, alguns se deslocaram para as áreas rurais, e outros, cerca de 350.000 partiram a l'etranger. E os dados coletados por Handerson (2015) revelam que, para os haitianos, não se trata de deixar o país como opção ou abandono, mas por chèche lavi: pela busca do que não se encontra no Haiti - estabilidade política e socioeconômica, serviços de saúde, infraestrutura, estudo, trabalho, dinheiro. "Nas palavras deles, na busca d'un mieux être (do bemestar), uma qualidade de vida cotidiana melhor do que aquela do Haiti" (HANDERSON, 2015, p. 74).

Para Bruneau (2004, p. 49), citado por Handerson (2015, p, 270), "Construir uma casa torna-se, frequentemente, um objetivo essencial para as famílias na diáspora", de modo que nos processos de imigração a construção de casas é relevante para os haitianos, pois está associada à sobrevivência e à hierarquia de aspirações. Segundo Handerson,

\footnotetext{
Não é só no Haiti que "emigrante" e "casa" estão imbricadas. No Brasil, no Suriname e na Guiana Francesas de uma forma quase indissociável o haitiano se encontra associado à ideia de "casa", mas nesses países, as casas onde les moram não eram chamadas de kay diáspora como no Haiti, mas, kay nan diaspora, casas na diáspora (2015, p. 280). (grifos do autor)
}

O uso dos termos kay diáspora data de 1990, ao se popularizar o termo diáspora entre os haitianos nos EUA e no Haiti, fazendo referência à pessoa que reside a l'etranger, retorna temporariamente ao Haiti e retorna a l'etranger. Nesse mesmo período a expressão passou a ligar-se às casas construídas pelas pessoas diáspora no Haiti. De acordo com o autor, supramencionado, a casa possibilita mensurar as formas pelas quais a mobilidade e a diáspora se vinculam de maneira intrínseca no mundo social haitiano - grupo de casas interligadas, organização, construção, trocas de solidariedade, circulação de pessoas, objetos e dinheiro, conforme mostrado em seus estudos.

Para o autor, pati (partir) vwayaje (viajar) estão ligadas à categoria de diáspora. Da parte dos que ficam, os viajantes são denominados de diáspora lokal (diáspora local), uma vez que permanecem pouco tempo a l'etranger. Seu poder aquisitivo lhes permite viajar frequentemente, pois possuem bens materiais no Haiti, negócios ou trabalham a l'etranger. Há uma expressão nativa que representativa da diáspora lokal "Li manje isit lan, epi l'ale bwe lót bó" (É aquele que come aqui [no Haiti] e bebe lá [no exterior] (HANDERSON, 2015, p.361).

Em relação àquele que sai por muito tempo a l'etranger, ao retornar ao Haiti é chamado de diáspora, sem o sufixo lokal, como aquele que vai e vem. Em outras variações, aquele que sai e nunca mais retorna é considerado como alguém que vive na diáspora, externa ao Haiti. Os que 
optam por não retornar, seja temporária ou definitivamente, não rompem vínculos com o país, pois ali mantém familiares, amigos, e no mais das vezes, enviam-lhes dinheiro, mercadorias e objetos. E sua opção está ligada às condições precárias que já mencionamos. Diáspora, assevera o autor, pode ser considerada uma categoria de interação, pois interliga o contexto haitiano com o de l'étranger, possibilitando a inter e a multiculturalidade proporcionada entre os diversos espaços de mobilidade transnacionais e o Haiti. Desse modo,

\footnotetext{
Diaspora pertence aos dois lugares ou mais, por viver nos dois ou entre os dois. Apessoa diaspora não está apenas em mobilidade, ela vive a circulação a partir dessas diferentes formas (...). A mobilidade faz parte da vida cotidiana da pessoa diaspora: ela constitui e vive permanentemente em novos espaços sociais e culturais (HANDERSON, 2015, p. 362).
}

Enfim, diz o autor, uma diáspora nunca abandona, verdadeiramente, o Haiti, mesmo que esteja a l'etranger, pois as suas referências lá permanecem. Isso fica visível em alguns depoimentos coletados pelo autor "Mwen pati kite Ayiti, men Ayiti pa kite'm" ( Parti, deixei o Haiti, mas o Haiti não me deixa) (HANDERSON, 2015, p. 363).

O termo diáspora também é usado para nomear ações, como " $\mathrm{W}$ 'ap fè bagay diáspora" (Está fazendo coisa de diáspora), em razão de alguma ação, comportamento, como aquisição de mansão, carro luxuoso, realizar uma grande festa. Ou se está com vestes caras, novas, exalando perfumes, ouve-se as pessoas dizerem: "On sanble yon diáspora" (Você parece um diáspora). Ainda, neste viés, o autor destaca que,

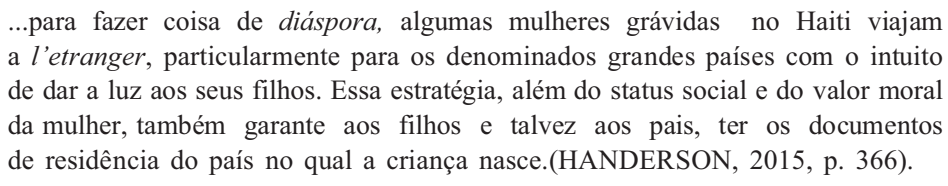

O autor destaca também a multiplicidade de sentidos do termo diáspora atribuídos tanto pelos que ficam quanto pelos que partem, tanto positiva quanto negativamente. Por exemplo, pode vir carregado de sentido pejorativo e acusativo - na situação em que aqueles que vão a l'etranger se sentem superiores aos que permanecem no país. E os que ficam, por sua vez, sentem-se ameaçados por "perder" espaços sociais e políticos para a população diáspora no Haiti e acusam "Diaspora pran plas mwen" (Diáspora ocupa meu lugar). Por seu turno, para os que ficam, o diáspora é incapaz de governar o país por sua situação de a l'etranger e não conhecer a realidade em seu entorno. (HANDERSON, 2015, p. 366). 
$\mathrm{O}$ autor ainda destaca em seu texto as questões de casamento com diáspora (homem e mulher), fidelidade, dentre outros aspectos. Assim, nesse universo é comum casar com diáspora, casar para viver na diáspora, incluir as casas diáspora, pois os haitianos espalhados pelo mundo representam quase a metade do número de pessoas que residem no País, estimado em 4,5 milhões, segundo dados do Ministério dos Haitianos Residentes no Exterior. Assim, muitas diáspora voltam ao País para casar, sendo que após o casamento eles continuam vivendo aletranje e o esposo ou a esposa permanece no Haiti, na espera que diáspora mande buscá-los por intermédio de processo de reunião familiar, que pode levar vários anos para se concretizar (HANDERSON, 2015, p. 368).

Vale aqui tomar de empréstimo uma citação mencionada por Handerson (2015, p.368) sobre tal modelo de matrimônio à distância "é um dos custos indesejáveis que a sociedade móvel paga pela sua incorporação no sistema econômico mundial" (RICHMAN, 2003, p.119).

\section{MigRAÇÕES: BREVE CENÁRIO}

O cenário contemporâneo das migrações revela que o mesmo fenômeno que se vê no Brasil e no Haiti presencia-se em todo o cenário mundial, uma vez que consequências do processo de reestruturação produtiva, que implica a mobilidade do capital, e consequentemente a mobilidade espacial de trabalhadores para diferentes regiões do globo, sem exceção.

Uma das linhas na qual os autores se inserem é o entendimento do contexto transnacional na atual fase da globalização econômica inserido nos processos macroestruturais de reestruturação produtiva, em suas diversas dimensões e implicações. Profundas reflexões têm estado na pauta de estudiosos, sobre as transformações econômicas, sociais, políticas demográficas e culturais em curso a partir, especialmente, das últimas duas décadas do século XX.

Entendemos, pois, que, se o homem migra desde os primórdios de sua existência, quer por questões climáticas, naturais, catástrofes, problemas econômicos, políticos, na busca de uma vida com mais dignidade, na atualidade, entender que a mobilidade humana e suas consequências é uma realidade do século XXI é uma temática que não pode ser ignorada nas agendas nacionais e internacionais. Urge que entendamos que migrantes, imigrantes, emigrantes e refugiados fazem parte de uma mesma história lutam pelo respeito e dignidade à vida, lutam pelos seus direitos universais, de homens e mulheres universais. É um desafio a todos e a todas entender as migrações internacionais como uma realidade social, da dinamica mundial, e não problema social: "Se trata, sí, de um tema complejo, urgente y 
necesario, que debe tener uns inserción prioritaria em la agenda de los derechos humanos" (MILESI, 2007, p. 9).

De acordo com Milesi e Ambros (2007, p. 9), a concepção forte ainda do migrante como "um fora da lei" tem contribuído para que os países criem legislações cada vez mais restritivas à livre circulação de estrangeiros em seus territórios. Em vista disso, a ponderação entre direito de o ser humano ir e vir e as políticas e legislações adotadas por países tem sido um dos primordiais objetivos do Direito Internacional Público. O clamor dos migrantes e refugiados em prol de seus direitos foi reforçado a partir da Declaração Universal dos Direitos Humanos, em 1948, complementado pelos Pactos Internacionais sobre Direitos Civis e Políticos e sobre Direitos Econômicos, Sociais e Culturais, na década de 1960 (AMBROS, 2007).

Ou ainda o debate leva-nos a aprofundar os temas sobre a defesa e os direitos do ser humano e de seu direito de cidadania universal.

\footnotetext{
Los migrantes y los refugiados son hmbres, mujeres y niños que debem ser respetados em virtud de su dignidad como personas más allá del régimen vigente o del lugar donde residen. Sus derechos no derivan del hecho de pertenecer a un Estado o Nación, sino de su condicón de persona, cuya dignidad no puede sufrir variaciones al mudar de un país a otro" (BICUDO, 2003, apud MILESI, 2007, p. 10).
}

$\mathrm{Na}$ atualidade, as migrações internacionais apresentam-se de modo ainda mais complexo e diversificado. Milesi e Marinucci (2005) apontam causas, como a exclusão crescente de alguns povos, países e regiões, decorrentes da economia globalizada; o aumento das desigualdades entre países do Norte e do Sul, as barreiras protecionistas que dificultam os países emergentes de terem competitividade no mercado, a propagação de conflitos e guerras, o terrorismo, a urbanização acelerada, a busca de melhores condições de vida e de trabalho, questões ligadas ao narcotráfico, à violência e ao crime organizado, questões étnico- religiosas; os movimentos vinculados às safras agrícolas, aos grandes projetos da construção civil e aos serviços em geral, as catástrofes naturais e situações ambientais.

O movimento que se viu em termos mundiais não foi diferente no cenário brasileiro, com a acentuada leva de imigrantes chegando a partir de 2010, caracterizando-se como o maior fenômeno dos últimos 100 anos.

Tal fenômeno, na contemporaneidade, consiste em um grande desafio para todos no que tange a seu entendimento, em todas as suas faces. De modo geral, os fluxos migratórios sempre lançaram inúmeros desafios às políticas públicas e sociais. No entanto, esses desafios constituem-se de modos e sob conceitos diversos, dependendo da conjuntura sócio-histórica de cada movimento. 
Para tanto, o espaço da academia é também a arena para se discutir e se entender a temática, e buscar estratégias para contribuir para a inserção social, educacional e profissional dos imigrantes da atualidade.

Ao acompanhar as dinâmicas sociais históricas é possível verificar características dos movimentos migratórios, amparados em razões diversas que levaram e levam as pessoas a se deslocarem, considerando os diversos modos de produção e, principalmente, o modo de produção capitalista. Neste, tal mobilidade espacial configura significativa importância e centralidade. Além da mobilidade crescente de pessoas, matérias-primas, capitais, dinheiro, informações, mercadorias, etc., também vem sofrendo deslocamento. Dentre os fatores que desencadeiam tais fenômenos pode-se citar as novas maneiras de produção e organização social do trabalho.

O registro da imigração no Brasil data da chegada dos portugueses no contexto da expansão econômica daquele país e colonização deste; o desenvolvimento da agricultura originou o movimento migratório forçado com o tráfego de africanos, tornados escravos, que durou cerca de três séculos (até 1850). Foram introduzidos na colônia e no Império cerca de 4 milhões de cativos (FERNANDES; CASTRO; KNUP; 2012, p. 137).

Zamberlam et al (2014) destacam que, com a chegada da Coroa Portuguesa no Brasil, em 1808, o Decreto 28 autorizou a criação de colônias urbanas com imigrantes de países estrangeiros e de 1812 a 1870 o Brasil recebe poucos imigrantes, de diversas nacionalidades - ingleses, suíços, franceses, poloneses, russos-ucranianos, turcos, libaneses, austríacos e lituanos.

Com a abolição da escravidão na segunda metade do século XIX, a necessidade de trabalhadores para atender ao cenário de expansão da produção de café originou a abertura para a imigração no Brasil. Concomitantemente, no cenário europeu, com a expansão da industrialização, o êxodo do campo para a cidade, e a não absorção de trabalhadores neste mercado de trabalho, contribuiu para que grandes levas adentrassem no Brasil a partir de 1870 (BRITO 2004 apud FERNANDES; CASTRO; KNUP, 2012, p. 138).

Desse modo, o fluxo imigratório para o Brasil tornou-se constante, e, registram os autores, entre 1870 e 1930 estima-se que cerca de 40 milhões de pessoas tenham migrado da Europa para a América, em especial para o Brasil.

A produção cafeeira, à época, consistia no principal produto de vinculação do Brasil ao mercado internacional. Em vista da necessidade de mão-de-obra e de aumentar a produção de alimentos, para atender ao mercado consumidor do eixo Rio - São Paulo e a visão de que os "imigrantes europeus seriam os únicos capazes de construir uma nação civilizada e moderna, o governo passou a incentivar a imigração europeia", ressaltam Fernandes, Castro e Knup (2012, p. 138). 
Esse movimento imigratório ocorria por duas vias - por agenciamento privado ou por iniciativas governamentais. A primeira fracassou, em razão da incapacidade de efetivação de trabalho livre, e as iniciativas governamentais é que passaram a assumir desde a divulgação, recrutamento, recepção e distribuição de imigrantes nas lavouras cafeeiras.

Os autores destacam que, nas últimas décadas do século XIX (1877 a 1903), a entrada de cerca de 2 milhões de trabalhadores, predominantemente italianos, que se fixaram e nas indústria e lavouras de café de São Paulo e Rio de Janeiro. Mencionam Levy (1974), que separa a dinâmica migratória no Brasil, no final do século XIX e início do século XX em dois períodos: 1) até 1876 entraram 350,117 imigrantes no país, dos quais $45,7 \%$ eram portugueses, $12,9 \%$ eram alemães e italianos, cerca de $6 \%$ eram espanhóis e $35,7 \%$ pertenciam a outras nacionalidades;2) de 1877 a 1903, há uma variação de nacionalidades e o período caracteriza-se pela acentuada leva de imigrantes italianos $(58,49 \%)$ e $20 \%$ de portugueses. Nesse ínterim, destaca o autor, entraram no Brasil 1.927.992 de pessoas, atingindo uma média anual de 71 mil imigrantes. O que se nota, declara o autor, é que até 1876 os portugueses consistiam no maior contingentes de imigrantes e já no ano seguinte, o número de italianos duplica em relação ao ano anterior. (LEVY, 1974, apud FERNANDES; CASTRO; KNUP, 2012, p. 139).

Nas primeiras décadas do século XX, a ideia de progresso ganha contornos mais densos e se dissemina o discurso sobre o desenvolvimento, que adentra o século XX, e em governos, como o de Washington Luís (19261930), "Governar é abrir estradas", expressão alusiva ao moderno. Prenuncia-se, assim, a instauração de um projeto de nação, baseado na industrialização, sob forte intervenção do Estado reestruturado e assentado em leis modernas, que, sobretudo, visa a forjar novas relações de trabalho (THEODORO, 2004, apud BERNARTT, 2006, p. 87). Com base nisso, sob a promessa de um futuro de progresso e bem- estar, anunciam-se no país diversas experiências de desenvolvimento, aliadas ao crescimento econômico.

Nessa conjuntura nacional, em 1930 e meados da década de 1940, o Brasil - ao inserir-se ao processo de reorganização da economia capitalista, em sua fase expansionista, precisa de uma nova reconfiguração espacial para poder "explorar melhor os recursos do território nacional". Inicia-se, então, a política nacional desenvolvimentista, por meio da industrialização massiva, cujo eixo principal passa a ser a política de "substituição de importações" (BERNARTT, 2006, p. 160).

Ainda segundo Bernartt (2006, p. 169), dentro desse contexto, tem lugar de destaque o processo de industrialização e o incentivo à ocupação de novas "fronteiras agrícolas". Dessa forma, "o processo de industrialização acaba por mobilizar, durante décadas, centenas de trabalhadores que à 
procura de ofertas de trabalho passam a reproduzir sua força de trabalho em outras áreas do território brasileiro". Com efeito, uma primeira ação em prol da ocupação e do desenvolvimento do interior do Brasil consiste em uma política de "ocupação de espaços vazios", denominada "Marcha para o Oeste". No dizer de Vargas, a Marcha incorpora "o verdadeiro sentido de brasilidade", uma solução para os infortúnios da nação. As políticas estatais dessa época que visam à substituição das importações e ao aumento das exportações tornam-se um dos fatores determinantes no direcionamento dos movimentos migratórios internos do século XX, destaca a autora.

Em vista disso, nesses anos entraram no Brasil 2.142.781 imigrantes, uma média anual de 79 mil pessoas (FERNANDES; CASTRO; KNUP, 2012, p. 139).

No final de 1930 são mencionadas as primeiras medidas de restrição à entrada de imigrantes no Brasil, originadas do reflexo da crise econômica mundial e local (crise do café) (BAENINGER; SOARES, 2009, apud FERNANDES; CASTRO; KNUP, 2012, p. 139), configuradas na fixação de cotas nas Constituições de 1934 e 1937. Assim, segundo Levy (1974), nos anos subsequentes à II Guerra Mundial (1942-1945), reduziu-se consideravelmente a entrada de imigrantes no Brasil, cerca de 2 mil por ano (FERNANDES; CASTRO; KNUP, 2012, p. 140).

A migração transnacional só voltará a assumir relevância no panorama brasileiro a partir de 1980, a partir de um intenso movimento de emigração de brasileiros em busca de melhores condições de vida em outros países. Segundo esses autores,

“...em nenhum momento ultrapassou 35 da população total, a sua distribuição foi concentrada em algumas regiões que sofreram impactos positivos, recebimento de remessas, como negativos, escassez de mão de obra" (2012, p. 140).

Mais recentemente, em razão da situação econômica em escala global, nota-se um novo movimento na história migratória brasileira, pois, de um lado, ocorre o fluxo de retorno dos que viviam no exterior e, de outro, o país passa a ser uma das novas rotas de imigrantes, de países do Hemisfério Norte, principalmente da Europa, e mais recentemente do continente africano e do Caribe. Esse movimento, segundo Zamberlan et al (2014, p. 5), demonstra que "O Brasil não é mais o país de imigração do século XIX e do XX, nem o país de emigração das décadas de 1980 e 1990. Somos hoje um país de imigração e emigração, trânsito e retorno de brasileiros..”.

Nesse cenário, segundo os autores, em 2010, o Brasil ostentava uma situação peculiar que possibilitou atingir uma taxa de crescimento econômico, medida em termos de PIB, da ordem de $7 \%$ em relação ao ano precedente. A expansão econômica por que passava o país gerou uma intensa necessidade de mão-de-obra, o que gerou um índice de desemprego dos 
mais baixos dos últimos anos e de maneira continuada, por um tempo sem precedentes no país. Tal demanda por mão-de-obra em não sendo suficientemente atendida gerou, entre o empresariado brasileiro, a procura por trabalhadores qualificados para atender a projetos de infraestrutura, de base e da indústria petrolífera (FERNANDES; CASTRO; KNUP, 2012, p.140).

$\mathrm{Na}$ atualidade, há cerca de 1.4 milhão de imigrantes no Brasil, o que representa $1 \%$ da população brasileira e $0,6 \%$ da população mundial de imigrantes (ZAMBERLAM et al, 2014). O Brasil ostentava em $2000 \mathrm{em}$ torno de 683 mil imigrantes, sendo: 384.906 europeus, 159.895 americanos (a maior parte de latinomericanos), 121.871 asiáticos. Já em 2006 esse número se elevou para 1.175 , e em dezembro de 2012 para $1.575 .643 \mathrm{com}$ a documentação regularizada. Estima-se que na atualidade ultrapasse 1,9 milhão, incluindo os indocumentados, considerado um número inexpressivo $(0,95 \%)$ diante da situação de países como Alemanha (8\%), Estados Unidos (16\%), Canadá (21\%) (ZAMBERLAN et al, 2014, p. 72).

Segundo esses autores, os dados revelam o aumento significativo, pois mais de 1,2 milhão de pessoas entraram no Brasil nestes anos reservados ao século XXI, sendo que dentre estes, cerca de 75 mil de países como Caribe, África e Extremo Oriente (2014, p. 72).

Na atualidade, o governo brasileiro ampliou a concessão de autorização de visto e trabalho, que passa de 42.914 em 2009 para 56.006 em 2010 atingindo $70.524 \mathrm{em}$ 2011. Isso indica uma acentuada elevação de 64, 3\% em dois anos (2009/2011) (FERNANDES, CASTRO, KNUP, 2012, p. 136).

$\mathrm{O}$ acirramento da crise econômica nos últimos anos contribuiu sobremaneira para a alteração do panorama da migração transnacional. As dificuldades para se atingir o intento de se chegar a um país mais desenvolvido tornaram-se restritas após o atentado de 11 de setembro de 2001, agravadas pelo desemprego em escala mundial, provocado por "bolhas" financeiras e imobiliárias e financeiras que afetaram de maneira mais acentuada os imigrantes, principalmente aqueles em situação não regular (FERNANDES; CASTRO; KNUP, 2012).

Pode-se dizer, então, que há "novos rosto" $" 12$ compondo a imigração brasileira formada pelo predomínio de latino-americanos, aos quais se somam os colombianos, mexicanos, portugueses, espanhóis, italianos, franceses e, recentemente, africanos, caribenhos e asiáticos. São, pois, novos rostos, novas culturas que, sem dúvida, já estão provocando inúmeros sentimentos na população brasileira que vai, desde a solidariedade, acolhimento, ajuda legal, até atos bárbaros, como agressões físicas e morais e demonstração de preconceito.

2 Expressão usada por Zamberlam et al (2014) em sua obra " Os novos rostos da imigração no Brasil". 
Em razão dos desafios prementes da complexidade do cenário mundial, nos quais se insere a temática da migração transnacional, o seu entendimento demanda estratégias de articulação e cooperação em rede interinstitucional. Em vista disso, as redes de cooperação têm se instituído como uma das alternativas para se enfrentarem os desafios contemporâneos, comuns para os atores da época. Com efeito, os objetivos comuns são os principais motivadores da formação de redes de cooperação.

Entretanto, mesmo com o esforço de diversas instituições governamentais, não- governamentais e acadêmicas, como as já mencionadas, no que tange ao enfrentamento do referido fenômeno, ainda é evidente no cenário brasileiro a carência de dados, a carência de fontes, os esparsos diálogos entre pesquisadores e empresas, escolas, ministérios, secretarias, conselhos, e com os próprios haitianos. Assim como, no sul e no norte os dados ainda são esparsos e fragmentados.

Chama-nos a atenção a maneira como o Estado brasileiro vem se posicionando em relação ao tema das migrações internacionais, bem como analisa o seu comportamento frente aos fluxos migratórios contemporâneos (REIS, 2011, p. 48).

Ainda não existe, de fato, uma política coerente e integrada no que tange às imigrações internacionais, conforme fora destacado em trabalhos de estudiosos, como Patarra e Duval (2011, p. 195), do Centro de Estudos Migratórios (CEM) - São Paulo, em estudo sobre as políticas públicas sobre migrações no Brasil e é parte integrante da obra Las políticas públicas sobre migraciones y la sociedade civil en América Latina (CHIARELLO, 2011), cujas análises se estendem sobre as políticas migratórias de Argentina, Colômbia e México.

Reis (2011), em estudo que remonta historicamente ao modus operandi do Estado brasileiro em relação ao tema das migrações internacionais, analisa o seu comportamento frente aos fluxos migratórios contemporâneos (REIS, 2011, p. 48).

A autora destaca que nos últimos tempos a política de imigração começou a ser percebida como parte importante da posição do Brasil em relação às migrações no plano internacional, o que explica as mudanças que estão sendo propostas no sentido de tornar mais coerente a posição do país em relação às migrações no sentido mais amplo (REIS, 2011, p. 49).

Sobre essa questão, Patarra e Duval (2011) também mencionam que se registra uma alteração crescente no parâmetro das políticas sociais de migração.

Nesse sentido, entendemos necessária a nova Lei de Migrações no País, para que se possa dar conta dessa problemática, já que hoje se obser- 
va um grande entrave legal, administrativo e de política pública para o entendimento de tais questões contemporâneas.

\section{MigraÇão NO CENÁRIO UNIVERSITÁRIO}

Para o entendimento de questões tão complexas da contemporaneidade, a noção de alteridade é importante. Como descendentes que somos de migrantes italianos, alemães ou de outras nacionalidades e habitante do espaço territorial que contempla o sul do Brasil, há cinquenta anos, expressões como: "território do sudoeste paranaense colonizado por migrantes italianos", "migrantes como pioneiros desbravadores do sudoeste", "migrantes que provocaram o desenvolvimento rural do sudoeste", "Levante dos Posseiros de 1957", "Guerra do Contestado", dentre tantas outras, fazem parte do cotidiano comum e acadêmico. Desde cedo, aqui, acostumamo-nos a ouvir relatos sobre "façanhas" de "pioneiros", "posseiros" na defesa de suas terras, e "migrantes italianos" que colonizaram o Sudoeste do Paraná e o oeste catarinense, dentre eles, os nossos avós que retrataram bem esse movimento, a seu modo: "Nóis dexemo as terra véia do Rio Grande pra vim pras terra nova do Paraná". Famílias, trabalhadoras rurais, como tantas outras, migraram para esses dois estados, entusiasmadas e "ludibriadas", por uma política desenvolvimentista do Estado Novo que visava ocupar os "espaços vazios" para o "progresso do Brasil", e que para isso, o Estado, associado a empresas colonizadoras, oferecia "lotes" gratuitamente a migrantes nas regiões fronteiriças do país. (BERNARTT, 2006).

Em que pesem essas experiências pessoais, cotidianas e comuns à gente desses lugares, a nossa aproximação acadêmica em relação à temática da migração, - recobre pouco mais de quatro anos ou mais especificamente aos últimos três, embora esse tema sempre tenha estado, de alguma maneira, atrelado e imerso nos estudos e nas pesquisas do Centro de Pesquisa e Apoio ao Desenvolvimento Regional, grupo de estudos inter e multidisciplinar, ao qual se vinculam pesquisadores e estudantes da Universidade Tecnológica Federal do Paraná - UTFPR Câmpus Pato Branco, desde 1995. Contudo, para esta pesquisadora, em 2006, ao defender a tese de doutorado intitulada "Educação e desenvolvimento: um estudo do

Tese defendida no Programa de Pós-Graduação em Educação da Unicamp (Departamento de História, Filosofia e Educação Brasileira), em feveiro de 2006.

14 O PPGDR nasceu de uma forte e intensa ligação com a comunidade regional, fortalecida desde desde o início da década de 1990 por intermédio da atuação do Grupo de Pesquisa Centro de Pesquisa e Apoio ao Desenvolvimento Regional (CEPAD) e do Grupo de Pesquisa Aplicada em Tecnologia de Biomassa e Meio Ambiente (BIOMA), 
sudoeste do Paraná, nos últimos cinquenta anos"13, a premência da temática veio à tona, embora não consistisse no alvo dos estudos naquele momento e mais recentemente, de 2010 em diante, com a criação do Programa de Pós-Graduação em Desenvolvimento Regional ${ }^{14}$, vinculado à Área do Planejamento Urbano,Regional/ Demografia, o tema foi ficando cada vez mais próximo de seus pesquisadores, além de ter sido impelido pela ampliação populacional no Sudoeste, com a chegada de grande número de migrantes, trabalhadores haitianos, a partir de 2010.

Em vista disso, no intuito de se somarem aos esforços nacionais e fazer eco junto a outros acadêmicos, pesquisadores da Linha Educação e Desenvolvimento do PPGDR, na qual esta pesquisadora se insere, desencadearamse alguns estudos visando buscar dados na região sudoeste do Paraná: "A mobilidade espacial da força de trabalho haitiana para a região Sudoeste do Paraná no século XXI e os impactos sociais, educacionais e linguísticos para esses trabalhadores e para a sociedade pato-branquense"15 (GIACOMINI; BERNARTT, 2013), "Condições de trabalho e educação de haitianos no sudoeste do Paraná: uma análise à luz do materialismo histórico ${ }^{15}$ " (GIACOMINI; BERNARTT, 2014), "Educação para haitianos em contextos escolares e não escolares: realidade e desafios no sudoeste do Paraná" (GIACOMINI; BERNARTT, 2014) e juntamente com o Programa de PósGraduação em Educação, da UNOCHAPECÓ, está em andamento a pesquisa "A inserção dos nacionais haitianos nos contextos educativos escolares e não escolares no oeste de Santa Catarina durante o período de 2012 a 2014" (BORDIGNON, PIOVEZANA; BERNARTT, 2015).

Ao nos inserirmos academicamente nesta temática, encontramos similaridade nos estudos de Cotinguiba e Pimentel (2012, 2013, 2014, 2015), além de contatos estabelecidos com pesquisadores de instituições, como: a Universidade Federal da Fronteira Sul, a Universidade Federal da Integração Latino Americana - UNILA, a Universidade Comunitária da Região de Chapecó - Unochapecó, a Universidade Regional Integrada do Alto Uruguai e das Missões (URI), a Fundação Universidade Federal de Rondônia (UNIR), o Centro de Referência e Direitos Humanos - UFFS, a Comissão Pró-Haiti-UNILA, a Associação dos Haitianos de Chapecó, a Casa Latinoamericana - CASLA, de Curitiba, as Pastorais dos Migrantes nos três estados do sul, as Associações de Haitianos, dentre outras, com os quais passamos a dialogar e a socializar estudos, metodologias, relatos e ações conjuntas.

os quais dão sustentação ao PPGDR. O Programa tem três linhas de pesquisa na Área de concentração Desenvolvimento Regional Sustentável: (1) "Ambiente e Sustentabilidade", (2) "Regionalidade e Desenvolvimento", (3) "Educação e Desenvolvimento". Disp. em:http://www.utfpr.edu.br/patobranco/estrutura-universitaria/ diretorias/dirppg/pos-graduacao/mestrados/ppgdr2/pagina-inicial

15 Trabalho de Conclusão de Curso de Letras, elaborado por Giacomini e Bernartt (2014). 
Tal relação possibilitou que, em parceria, pesquisadores de tais instituições (docentes, estudantes de pós-graduação e membros de organizações) ${ }^{16}$, aprovassem junto ao Conselho Nacional de Desenvolvimento Científico e Tecnológico (CNPq/MCTI), dois projetos de pesquisa: 1) "A mobilidade espacial da força de trabalho haitiana no século XXI e impactos para o desenvolvimento regional na percepção de educadores, industriais, comerciantes e profissionais da saúde: um estudo deste fenômeno nas regiões Sul e Norte", aprovado na Chamada MCTI/CNPQ/MEC/CAPES N ${ }^{\circ}$ 22/2014 na área das Ciências Humanas, Sociais e Sociais Aplicadas (20142016); 2) "Práticas institucionais de agentes públicos e atores da sociedade civil com migrantes e refugiados nas regiões sul e norte do Brasil: dos direitos universais à realidade de acesso à educação, trabalho, saúde e seguridade social", aprovado na Chamada CNPq/ MCTI No 25/2015 das Ciências Humanas, Sociais e Sociais Aplicadas.

Assim, pelos diálogos profícuos entre os pesquisadores, pelo estudo do complexo cenário imigração/migração em âmbito nacional, local e internacional que os une e pela urgência em se tratar o tema, os pesquisadores ampliaram a parceria congregando outras instituições, ampliando as parcerias e submeteram um projeto ao Edital do Programa de Extensão Universitária PROEXT $2016^{17}$ (MEC), visando à criação de um Observatório "Observatório do Fluxo das Imigrações de Trabalhadores Haitianos: Sul e Norte do Brasil" "18, que será lançado em fevereiro de 2016, na UTFPR Câmpus Pato Branco. O projeto envolve vinte e um pesquisadores (docentes, estudantes e atores da sociedade civil organizada) de instituições como UTFPR, UNOCHAPECÓ, UFFS, URI, UNILA, UNIR, além de entidades, como a Associação dos Haitianos de Chapecó (ASHC) ${ }^{19}$, o Centro de

16 O projeto envolve 12 pesquisadores professores e estudantes, vinculados a programas de pós-graduação, do Sul - : Programa de Pós-Graduação em Desenvolvimento Regional - PPGDR, da Universidade Tecnológica Federal do Paraná, o Programa de Pós-Graduação em Educação (PPGE) e Programa de Políticas Sociais e Dinâmicas Regionais, da Universidade Comunitária da Região de (UNOCHAPECÓ), o Programa de Pós-Graduação em Educação (PPGDU), da Universidade Regional Integrada do Alto Uruguai e das Missões (URI), campus de Frederico Westphalen, pesquisadores da Universidade Federal da Fronteira Sul - Campus Chapecó, e o Programa de Pós-Graduação em História e Estudos Culturais, da Universidade Federal de Rondônia (UNIR).

17 O Programa de Extensão Universitária (ProExt) tem o objetivo de apoiar as instituições públicas de ensino superior no desenvolvimento de programas ou projetos de extensão que contribuam para a implementação de políticas públicas. Criado em 2003, o ProExt abrange a extensão universitária com ênfase na inclusão social. (Disponível em http://portal.mec.gov.br/index.php?option=com_content\&view=article\&id=12241\&Itemid= 488

18 O projeto foi submetido ao PROEXT 29016, na Área - Ciências Sociais Aplicadas, Direito , Direitos Especiais, Linha 16: Justiça e direito do indivíduo privado de liberdade, Subtema - 4.16.14 Observatórios de migrações e práticas de comunicação social e organizacional de grupos e pessoas migrantes. E obteve o $7 .^{\circ}$ lugar nacional no resultado classificatório.

19 No sul do Brasil os trabalhadores haitianos se organizam em associações como estratégia de luta pelos seus direitos. Disponível em: https://www.facebook.com/associacaohaitianosdechapeco?fref=photo 
Referência em Direitos Humanos Marcelino Chiarello da UFFS ${ }^{20}$ e a Casa Latino Americana de Curitiba (CASLA) ${ }^{21}$.

O objetivo comum entre os envolvidos refere-se ao aprofundamento e à ampliação de conhecimentos e criação de banco de dados e repositório, sobre fluxos imigratórios de trabalhadores haitianos nestas regiões, por meio de parcerias institucionais estabelecidas entre universidades, grupos de pesquisa, ONGs, associações, igrejas, pastorais, observatórios nacionais, ministérios, CNIg, dentre outros, para estudos teóricos e empíricos, socialização de informações, dados, relato de experiências, criação de estratégias e ações conjuntas, melhor inserção social, educacional e melhoria de condições de vida destes imigrantes e fornecimento de subsídios para políticas sociais dirigidas às imigrações internacionais do Brasil, especialmente, para essas regiões.

Ainda é importante destacar um outro elemento que congrega grande parte destes pesquisadores, o "Grupo de Estudos sobre Imigrações para a Região Oeste de Santa Catarina (GEIROSC) 22", criado em 2014, junto à Universidade Federal da Fronteira Sul (UFFS) Campus Chapecó, cujos integrantes vinculam-se a diferentes universidades e entidades da região sul e do Brasil ${ }^{23}$ e, pelas formações e qualificações de seus integrantes, compõe-se como um grupo interdisciplinar e interinstitucional para estudos e ações sobre o tema das imigrações nas mais variadas áreas do conhecimento e da práxis. Na atualidade, o grupo compõe-se por docentes, discentes (brasileiros e haitianos), e técnicos administrativos que atuam interdisciplinarmente nas cinco linhas de estudo e pesquisas (ainda em construção), de acordo com as qualificações dos integrantes e interesses de estudo, as quais convergem e dialogam entre si, quais sejam: Imigração e Cidadania, Imigração e Direitos Humanos, Imigração e Educação, Imigração e Atenção à Saúde e Imigração e Trabalho. Em cada uma delas há pesquisas e trabalhos em desenvolvimento, desde trabalhos de conclusão de

20 Instituído em 30/03/2015, o Centro de Direitos Humanos Marcelino Chiarello - CDRH da UFFS é fruto de uma cooperação entre a Universidade Federal da Fronteira Sul e a Secretaria de Direitos Humanos da Presidência da República (SDH) e busca a efetivação dos direitos humanos e o combate a todas as formas de preconceito, intolerância, discriminação, desrespeito e violência na Mesorregião da Fronteira Sul.(Disponível em https:// www.facebook.com/crdhuffs/info?tab=page_info)

21 A CASLA (Casa Latino-Americana) é uma instituição que promove o respeito e os direitos dos imigrantes. Foi fundada em junho de 1985, em Curitiba, Paraná pela iniciativa de muitos paranaenses engajados na resistência democrática do continente. (Disponível em http://www.casla.com.br/index.php)

22 GEIROSC - Disponível em: https://www.facebook.com/groups/geirosc.br/?fref=ts

23 Os integrantes pertencem a instituições de ensino superior como: Universidade Federal da Fronteira Sul (UFFS Campus Chapecó), Universidade Comunitária da Região de Chapecó (UNOCHAPECÓ), Universidade Tecnológica Federal do Paraná (UTFPR Campus Pato Branco), Diocese de Chapecó e Congregações Religiosas. Integram o grupo graduandos, mestrandos, doutorandos, mestres e doutores, com qualificações nas áreas de: Humanidades: Educação, Linguística, Pedagogia, Ciências Sociais Aplicadas: Direito; Saúde: Enfermagem,Psicologia. 
curso (TCC), graduação e especialização, projetos de iniciação científica (IC), artigos, textos, dissertações, teses.

Destaca-se, ainda, a participação dos pesquisadores em audiências públicas sobre a temática, comitês de trabalho, seminários, colóquios, rodas de conversa, aulas de língua portuguesa para haitianos e senegaleses, orientações quanto à documentação para migrantes, atividades culturais, entre outras ações de destaque. A exemplo disso, registra-se o Encontro de Pesquisadores sobre Imigrações/Relatos de experiências sobre acolhimento de imigrantes: Desafios para a Pós-Graduação em Educação, como parte do Seminário sobre desafios da Pós-Graduação Stricto Sensu em Educação. $\mathrm{Na}$ Região Sul, realizado pelo Programa de Pós-Graduação em Educação da Unochapecó, em parceria com as instituições já mencionadas (UTFPR,UFFS,URI,UNOESC), entre outras.

Também é interessante destacar que em todas as regiões brasileiras, em relação à nova leva de imigração, pode-se dizer que há um notório silenciamento por parte dos órgãos públicos, sejam estaduais ou municipais, secretarias de educação e saúde, assistência social, especialmente por parte das instituições de ensino superior.

Por fim, destacam-se vários estudos em fase de desenvolvimento pelos pesquisadores e, dentre eles, os de grande interesse - contribuições dos imigrantes no desenvolvimento das regiões. Estima-se ainda para este ano os primeiros resultados.

\section{REFERÊNCIAS BIBLIOGRÁFICAS}

ALTO COMISSARIADO DAS NAÇÕES UNIDAS PARA REFUGIADO (ACNUR). Refúgio no Brasil: uma análise estatística (janeiro de 2010 a outubro de 2014), Brasília: ACNUR, 2014.

AMBROS, S. (Org). Políticas públicas para as migrações internacionais. Disponível em:

http://www.dhnet.org.br/dados/livros/dht/livro_migracoes_fantazzini.pdf

MILESI, R.; AMBROS, S. Políticas Públicas para as Migrações Internacionais - Migrantes e Refugiados. 2a . ed. revista e atualizada. Brasília: Alto Comissariado das Nações Unidas para Refugiados; Instituto Migrações e Direitos Humanos; Comissão de Direitos Humanos e Minorias da Câmara dos Deputados, 2007.

BAENINGER, R.; SOARES, W. Perfil migratório do Brasil. Texto preliminar/OIM. Brasília: 2009 (mimeo).

BARATA, Iamê. Migrar é um direito humano. O estrangeiro- Brasil país de imigração. 2012. Disponivel em: http://oestrangeiro.org/2012/06/17/migrar-e-um-direito-humano/ Acesso em 20 Set. de 2015 . 
BERNARTT, M.L. Desenvolvimento e ensino superior: um estudo do sudoeste do Paraná nos últimos cinquenta anos. Tese de Doutorado. Programa de Pós-Graduação em Educação. Universidade Estadual de Campinas, Campinas-SP, 2006.

BORDIGNON, S. A. F.; PIOVEZANA, L.; BERNARTT, M. L. Inserção dos imigrantes haitianos nos contextos educativos escolares e não-escolares no oeste de Santa Catarina. Projeto de Mestrado. Programa de Pós-Graduação em Educação. UNOCHAPECÓ, Chapecó, 2015.

BORDIGNON, S. A. F.; PIOVEZANA, L.; BERNARTT,M.L.. Inserção dos imigrantes haitianos nos contextos educativos escolares e não-escolares no oeste de Santa Satarina. Projeto de Mestrado. Programa de Pós-Graduação em Educação. UNOCHAPECÓ, Chapecó, 2015.

BRITO, B. Crescimento demográfico e migrações na transição para o trabalho assalariado no Brasil. Revista Brasileira de Estudos de População, Campinas, v 21, n. 1, p. 5-20, 2004.

CHIARELLO, L. (coord). Las politicas públicas sobre migraciones y lasociedad civil em América Latina: los casos de Argentina,Brasil,Colombia e México. Scalabrini International Network, New York, 2011.

COTINGUIBA, G. C.; PIMENTEL, M. L. Apontamentos sobre o processo de inserção social dos haitianos em Porto Velho. 2012. Disponível em: $<$ http://nx.scalabriniane.org smr/wp-content/uploads/2012/09/ARTIGO-HAITIANOS-EM- PORTO-VELHO-MAIO2012.pdf>. Acesso em: Agosto de 2015.

COTINGUIBA, G; PIMENTEL, M. L. Relato sobre imigração na Amazônia ocidental brasileira: Haitianos em Porto Velho. Revista Nossa América Hoy, São Paulo, mar. 2013. Disponível em: $<$ http://www.memorial.org.br/wp- content/uploads/2013/05/nossa_america_hoy_ed_03.pdf $>$. Acesso em: Set. de 2015.

COTINGUIBA, M. L. P. COTINGUIBA, G. C. Imigração haitiana para o Brasil: os desafios no caminho da educação escolar. Revista Pedagógica, UnoChapecó, v.17, n.33, p. 61-87, Ju1./Dez. 2014.

COTINGUIBA, G. Imigração haitiana para o Brasil - a relação entre trabalho e processos migratórios. Dissertação (Mestrado em História e Estudos Culturais). Fundação Universidade Federal de Rondônia/UNIR, 2014. Disponível em http://www.migrante.org.br/migrante/images/ arquivos/dissertacao_geraldo_castro_2014.pdf. Acesso em: 18 Jul. 2015.

CORSO, G., ZAMBERlAM, J., BOCCHI, L., CIMADON, J. M. Imigrante - A Fronteira da documentação e o difícil acesso às políticas públicas em Porto Alegre/ Porto Alegre: Solidus, 2013.

Relato sobre imigração na Amazônia ocidental brasileira: Haitianos em Porto

Velho. Revista Nossa América Hoy, São Paulo, mar. 2013. Disp em: $<$ http:/ /www.memorial.org.br/wpcontent/uploads/2013/05/nossa_america_hoy_ed_03.pdf $>$. Acesso em: 01 Jul. 2015.

FERNANDES, D.M; CASTRO, M. C. G. de; KNUP, S. P. Fluxo da mão de obra da Europa para o Brasil. In: Economia, parlamentos, desenvolvimento e migrações: as novas dinâmicas bilaterais entre Brasil e Europa / [Tradução Mónica Baña]. - Rio de Janeiro : Konrad-Adenauer-Stiftung, 2012.

GIACOMINI, T. BERNARTT, M.L. A mobilidade espacial da força de trabalho haitiana para a região Sudoeste do Paraná no século XXI e os impactos sociais, educacionais e linguísticos para esses trabalhadores e para a sociedade pato-branquense. Trabalho de Conclusão de Curso. Licenciatura em Letras-Inglês. UTFPR Câmpus Pato Branco, Pato Branco, 2013. 
Condições de trabalho e educação de haitianos no sudoeste do Paraná: uma análise à luz do materialismo histórico. Trabalho de Conclusão de Curso. Especialização em Letras.

Educação para haitianos em contextos escolares e não escolares: realidade e desafios no sudoeste do Paraná. Projeto de Mestrado. Programa de Pós-Graduação em desenvolvimento Regional (PPGDR), UTFPR Câmpus Pato Branco, Pato Branco, 2015.

HÄBERLE, Peter. Os problemas da verdade no Estado constitucional. Tradução Urbano Carvelli. Porto Alegre: Sérgio Antonio Fabris, 2008.

IMDH. Instituto Migrações em Direitos Humanos. www.migrante.org.br Acesso em 25 de novembro de 2015 .

LEVY, M. E. F. O papel da migração internacional na evolução da população brasileira (1872 a 1972). Revista Saúde Pública, São Paulo, sup1, 8, p-49-90, 1974.

MILESI, R. LACERDA, R. Políticas públicas para las migraciones internacionales: migrantes e refugiados. 2. ed. ACNUR; IMDH; CDHM. Brasília, Alliance Gráfica, 2007.

MILESI, R. MARINUCCI, R. Migrações Internacionais: em busca da cidadania universal. In: Revista Sociedade em Debate, Pelotas, 11(1-2): 13-37, dez./2005. Disponível em:file://C:/ Users/sidnei/Downloads/444-1653-1-PB.pdf Acesso em outubro de 2015.

OLIVEIRA, L.L.O. O Brasil dos imigrantes. 2 ed. Rio de Janeiro: Zahar Ed. 2002.

ONU. Declaração Universal Dos Direitos Humanos. 1948. Disponível em: http:// unesdoc.unesco.org/images/0013/001394/139423por.pdf acesso em outubro de 2015

PATARRA, N. L. Migrações internacionais: teorias, políticas e movimentos sociais. Estudos Avançados, São Paulo, v.20, n.57, p.7-24, 2006.

PATARRA N.; FERNANDES, D. Desenvolvimento e migração. In: CHIARELLO, L. (coord). Las politicas públicas sobre migraciones y lasociedad civil em América Latina: los casos de Argentina,Brasil,Colombia e México. Scalabrini International Network, New York, 2011.

REIS, R. R.. A política do Brasil para as migrações internacionais. Revista Contexto Internacional, Jan/Jun.33(1)., 2011.

RICHMAN, Karen. Miami Money and the home gal. In: Anthropology and humanism, 27 (2): 2003, 119-132.

SANTOS, M. Sociedade e Espaço: a formação social como teoria e como método. Boletim Paulista de Geografia, São Paulo, n. 54, 1987.

SAYAD, A. A imigração ou os paradoxos da alteridade. Tradução Cristina Murachco. São Paulo: Editora da Universidade de São Paulo, 1998.

THEODORO, Mário. A questão do desenvolvimento - uma releitura. IN: RAMALHO, J. P \& ARROCHELlAS, M. H. (Orgs). Desenvolvimento, subsistência e trabalho informal no Brasil. São Paulo: Cortez; Petrópolis, RJ: Centro Alceu Amoroso Lima para a Liberdade- CAAL, 2004. ZAMBERLAM, Jurandir et al. Os novos rostos da imigração no Brasil: haitianos no Rio Grande do Sul. Porto Alegre: Solidus, 2014.

ZAMBERLAM, J., CORSO, G., BOCCHI, L., CIMADON, J. M. Os novos rostos da imigração no Brasil: haitianos no Rio Grande do Sul. Porto Alegre/ Porto Alegre: Solidus, 2014. 